\title{
On the Cultivation of Drosera magnifica Rivadavia \& Gonella, THE FACEBOOK SUNDEW
}

Nigel HewitT-Cooper • The Homestead • Glastonbury Road • West Pennard • Somerset BA6 8NN

-UK・sales@hccarnivorousplants.co.uk

To be afforded the opportunity to cultivate a new species is something one should always regard as a privilege. To have the chance to grow a species such as D rosera magnifica goes beyond this, and I have been one of the fortunate few who have been gifted with the material to attempt cultivation.

This unique species, the largest in Latin America, was 'discovered' by Paulo Gonella in 2013, amongst a collection of field photographs taken by amateur botanist Reginaldo Vasconcelos. The images had sat online for some time before this incredible species of D rosera was noticed. Vasconcelos had been exploring the Pico do Padre Angelo, in eastern Minas Gerais, Brazil, and posted his findings on Facebook. Here it was found in a vegetation type known as campos rupestres, Portuguese for rocky fields, an area characterised by montane shrubby vegetation at an elevation of between 700 to $2000 \mathrm{~m}$. Gonella subsequently visited the location, and the species was formally described in 2015 (Gonella et al. 2015).

Drosera magnifica is found at an approximate elevation of $1500 \mathrm{~m}$, an interesting observation when one considers its cultivation, as this tells us that the species appreciates the coolness that this elevation affords. It is found growing in well-drained organic matter and sand over sandstone, and in the company of orchids, bromeliads, and Vellozia (Fig. 1). It is the largest D rosera species in the Americas and forms a woody stem to $120 \mathrm{~cm}$, which scrambles through the surrounding vegetation, topped by a rosette of erect/semi-erect filiform leaves to $24 \mathrm{~cm}$ in length. More details of its discovery and a detailed description can be found in Gonella et al. (2015), Gonella (2016), and Robinson et al. (2017).

Bearing in mind the habitat information, it was assumed that the cultivation of this species would follow that of other South American species from similar habitats and elevations, and hence, it appears to enjoy conditions similar to Drosera spiralis, along with D. graminifolia, with which it is closely allied.

Seeds were sown on a mix of equal parts quartz sand and peat and kept in a terrarium with a daytime temperature of $22^{\circ} \mathrm{C}$ and a nighttime temperature of $15^{\circ} \mathrm{C}$. They received a photoperiod of 16 hours.

In these conditions, germination took between four and six weeks, and other growers have reported germination in a similar timescale and even less for in-vitro germination, an aspect I shall leave to another to write about (see articles by Hausherr and by Reimansteiner, this issue).

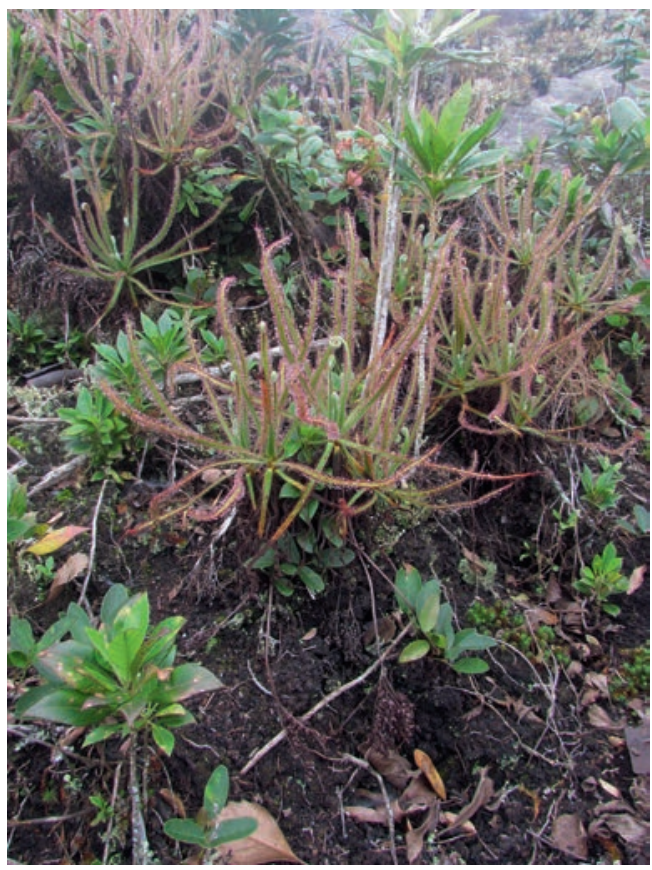

Figure 1: Adult Drosera magnifica in habitat. Photo by Paulo Gonella. 


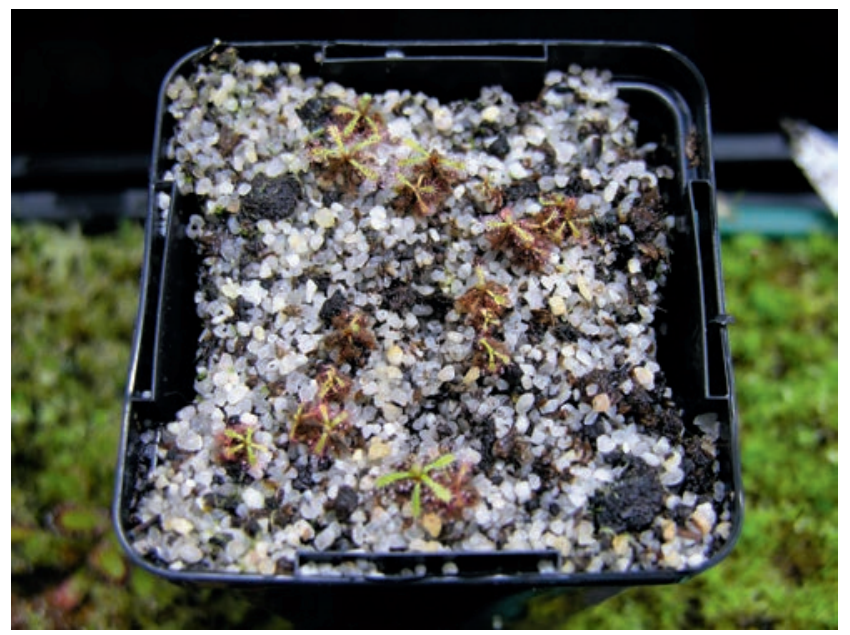

Figure 2: Seedlings kept in terrarium conditions remain small. These are ca. 12 months old.

Interestingly, I sowed a few seeds in greenhouse conditions, and none germinated. Moving the pot subsequently into the terrarium, and the higher humidity, prompted them to germinate and grow. The plants remained small, and indeed, a pot which remains in the terrarium as a backup, are still at the seedling stage one year after sowing (Fig. 2).

I removed a number of the young plants from the terrarium in the autumn, once the risk of high temperatures had passed, and potted them individually into $5 \mathrm{~cm}$ pots in the same mix as above and placed them in greenhouse conditions. These plants have continued to grow over the winter months, with a minimum temperature of $10^{\circ} \mathrm{C}$, and with LED lights as a supplement (Fig. 3).

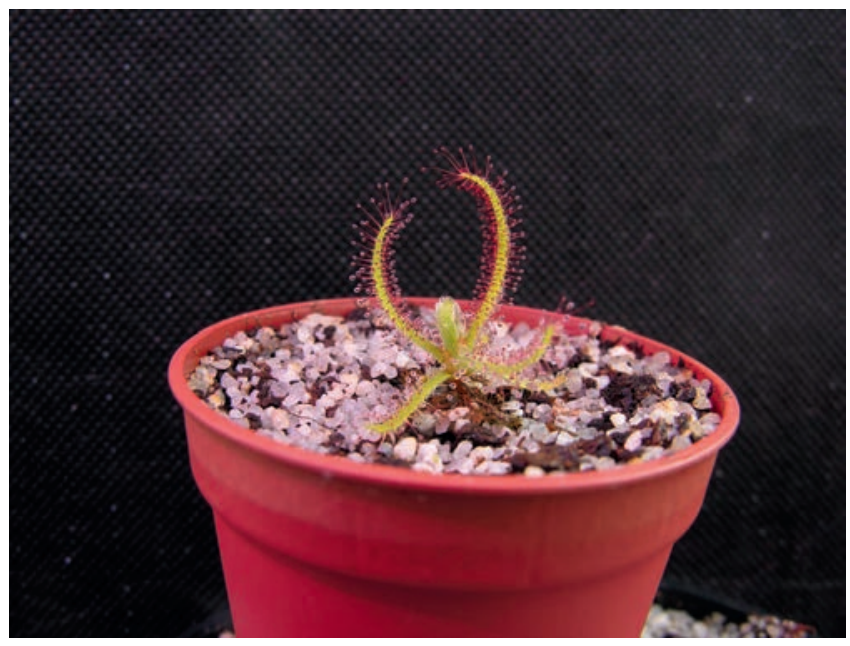

Figure 3: A juvenile Drosera magnifica, ca. 12 months from germination. 
Bearing in mind the winter in habitat is cool and drier, I kept them damp, rather than wet, and they have continued to grow, albeit slowly, with the largest now at approximately $12 \mathrm{~mm}$ in height. The application of a half strength dose of fertiliser (Orchid Focus Grow (20:10:20)), every two weeks seems to have benefitted the plants over the winter months, as did the application of dried fragments of bloodworm, though this does carry the risk of rotting the leaves in grey damp conditions, so is best carried out in the spring and summer months. I rather suspect this is a species that if fed well, will grow well; this has certainly been proven so far.

To re-cap, and emphasise my greenhouse conditions, the plants will move to larger containers of the same mix, sit in shallow water for the summer, and not overheat. For the winter, they seem to appreciate a drier mix, and remain just damp. In short, the same conditions as D. spiralis and D. graminifolia, which in my experience can also rot if kept too wet over the winter months. As the plants grow, I imagine they'll like a deep pot for their roots, this in itself aiding to keep the right amount of moisture present for the plants at this critical time.

I've heard this plant's culture is compared to that of D. regia. This draws important parallels, as that species is more readily grown by hobbyists, and therefore sends out the valuable signal that if you can succeed with D. regia, you can succeed with D. magnifica. From what I've seen so far, and remember, these are the embryonic days of cultivation of this unique species, that is exactly what I'm finding.

\section{References}

Gonella. P.M. 2016. Deep in the web, up in the hills: the discovery of D rosera magnifica, the "Facebook sundew". Carniv. P1. Newslett. 45(3): 107-112.

Gonella, P.M., Rivadavia, F., and Fleischmann, A. 2015. D rosera magnifica (Droseraceae): the largest New World sundew, discovered on Facebook. Phytotaxa 220(3): 257-267.

Hausherr, L. 2018. In vitro culture of D rosera magnifica. Carniv. Pl. Newslett. 47(3): 124.

Reimansteiner, M. 2018. Propagation of D rosera magnifica Rivadavia \& Gonella in vitro. Carniv. P1. Newslett. 47(3): 123.

Robinson, A.S., Gibson, R., Gonella, P., McPherson, S., Nunn, R., and Fleischmann, A. 2017. D rosera of the World, Volume 3: Latin America \& Africa. Redfern Natural History Productions, Poole. 